\title{
Inhibition of sham feeding by hyperosmotic gastric infusions in rat
}

\author{
DOUGLAS G. MOOK and DAVID K. YOO \\ University of Virginia, Charlottesville, Virginia
}

\begin{abstract}
In rats with esophagostomy and gastric cannulas, oral and postingestive events that accompany feeding can be varied independently. In food-deprived but not water-deprived rats, infusion of hypertonic $\mathrm{NaCl}$ concurrent with glucose sham feeding rapidly inhibited feeding, relative to isotonic $\mathrm{NaCl}$, and was about as effective as i.g. glucose itself in bringing the ingestive bout to an end. This equivalence held over a range of glucose concentrations, or a complex liquid diet, when these were offered for oral ingestion. The inhibition was not accompanied by responsiveness to water. These findings extend earlier ones with water-deprived rats and show that osmotic factors can inhibit feeding without evoking thirst.
\end{abstract}

Intake of sweet solutions has been a useful model of the interplay of excitatory and inhibitory controls over a bout of ingestion. The sweet taste of glucose or sucrose triggers an initial positive-feedback component (e.g., Davis \& Smith, 1990) and leads to vigorous ingestion in fooddeprived rats. However, especially at high concentrations, ingestion rapidly comes to an end. This results from postingestive control, as is shown, for example, by sham-feeding studies in which intake at high concentrations is greatly augmented, relative to real feeding (e.g., Mook \& Wagner, 1988; Weingarten \& Watson, 1982). Conversely, intragastric (i.g.) loads of glucose, which bypass the oral receptors, decrease the concurrent (Mook, 1963) or subsequent (McCleary, 1953) intake of these sugars.

The postingestive load does not have to be nutritive to produce this effect. In a classic series of experiments, McCleary (1953) showed that i.g. loads of hypertonic $\mathrm{NaCl}$, as well as of glucose, would depress subsequent glucose intake. Mook (1963) substituted the systemic effects of $\mathrm{NaCl}$ for those of glucose by infusing $\mathrm{NaCl}$ i.g., as the rats sham drank a glucose solution. Hypertonic $\mathrm{NaCl}$ was about as effective as glucose itself in limiting glucose ingestion, showing that the carbohydrate meal can be limited by some consequence of hypertonicity of gastric contents in the absence of nutrients. The latter methodi.g. infusion concurrent with sham feeding-isolates the effects of osmotic factors more convincingly than, say, i.g. or systemic preloads before a real meal. In the latter case, it is unclear whether the osmotic challenges operate in their own right or by modulating nutritive or other chemospecific signals that the real meal generates.

To date, however, only one such study has been reported, and it was conducted in water-deprived rats. The

This research was supported by NSF Grant BNS-8612653. We thank David Hill and Emilie Rissman for comments on a preliminary version of the manuscript. Correspondence should be addressed to Douglas G. Mook, Department of Psychology, Gilmer Hall, University of Virginia, Charlottesville, VA 22903. present investigation extends these earlier findings to rats that are not water deprived.

In addition to its empirical interest, such an extension asks a question about the osmotic inhibition of feeding. When water-deprived rats are used, the effect of hypertonic $\mathrm{NaCl}$ may depend on its augmenting an already existing hydrational problem. Even in rats that are not water deprived at the outset, osmotically active preloads (e.g. , of $\mathrm{NaCl}$ ) have usually been given in quantities that are dipsogenic in their own right (e.g., see Jacobs, 1964). Perhaps, then, the suppression of feeding in such experiments is secondary to evocation of thirst. We show, however, that hypertonic $\mathrm{NaCl}$ can be effective in ending a glucose meal, in quantities insufficient to evoke behavioral signs of thirst.

\section{GENERAL METHOD}

\section{Subjects}

Adult female Sprague-Dawley rats, $310-340 \mathrm{~g}$ preoperative weight, were used as subjects. All had been prepared with esophageal fistulas and with chronic intragastric cannulas to permit both nutritional maintenance and the experimental delivery of fluids into the stomach. They were maintained at $80 \%-85 \%$ of preoperative weight by limited feeding of liquid diet (see below) at concentrations adjusted each day as required for body-weight stasis. All rats had been operated several months before the present experiments, and all had had extensive experience at sham feeding various solutions in previous experiments.

\section{Apparatus}

The rats were maintained in $20 \times 25 \times 18 \mathrm{~cm}$ modified wiremesh cages equipped with sliding wire-mesh tops to which a watertight swivel joint and tether (see below) were attached. They were housed in a climate-controlled vivarium, with a 12-h light:dark cycle (light onset 7 a.m.).

While the animals were maintained in their home cages, automatic timing devices activated a peristaltic pump (Manostat 72-501000 ) at programmed intervals. The pump delivered liquid meals of physiological size and spacing through the tether and the cannula into the stomach (see below).

The tether consisted of an 8 -in. (length) polyethylene tubing (PE 90), protected by a light spring wire (1.5 mm o.d.). The tether 
ended at the top of the cage, where it was connected to the watertight swivel joint. The inlet to the swivel was in turn connected by plastic tubing to the pump or to a syringe as required. The swivel and tether combination permitted the animal complete freedom of movement.

Behavioral testing was conducted in identical cages, also equipped with swivel and tether, in a separate room.

\section{Surgery}

Preparation and maintenance of esophagostomized rats have been described elsewhere (Mook \& Wagner, 1987), though we have modified our procedure in a number of ways described briefly here.

Gastric canuula. Surgery was performed under methoxyflurane anesthesia. A silicone-rubber cannula was inserted into the stomach through laparotomy; it was held in place by a purse-string suture and by a small square of Mersilene mesh, cemented to the tube and sutured to the stomach wall. The tube was exteriorized between the scapulae, where it was friction-fit over a cutoff 19-ga stainless steel hypodermic needle with Luer hub, bent to $135^{\circ}$. The assembly was held in place by a rectangle of Marlex mesh cemented to the needle hub and implanted under the skin. The needle hub protruded upward and back from the animal's dorsal surface to permit connection to the tether (see below).

Esophagostomy. A week or more after the cannula implantation, esophagostomy was performed under methoxyflurane anesthesia. Through a midline incision at the throat, the sternohyoid muscle was divided down the midline; the esophagus was dissected free and transected. The upper end of the esophagus was brought to the skin of the throat and sutured to an oval-shaped paramidline wound to provide a natural fistula. The lower end of the esophagus was closed with a suture ligature, and the midline incision was closed with interrupted nylon sutures. Chloramphenicol ( $7 \mathrm{mg} / \mathrm{kg}$ per day) was administered for 3 days as prophylaxis.

\section{Maintenance}

An esophagostomized rat is dependent upon i.g. infusions for nutrition and hydration. The rats in this experiment received six intragastric meals per day, each lasting $15 \mathrm{~min}$ and delivering $20 \mathrm{ml}$ of liquid diet, at 3-h intervals onset to onset. The diet, described elsewhere (Mook, Wagner, \& Hartline, 1991), was diluted with water each day as necessary to maintain stable body weight, to a total of $120 \mathrm{ml}$ of fluid per day. The first meal began at noon each day and the last at $3 \mathrm{a} . \mathrm{m}$., so that the experiments conducted at 9 a.m. followed $6 \mathrm{~h}$ of deprivation.

This regimen provides generous hydration, which is required for maintenance of esophagostomized animals in optimal condition. In our experience, this regimen leaves such rats behaviorally unresponsive to water, even after $6 \mathrm{~h}$ of deprivation of food and fluid. In the present rats, this was confirmed by occasional checks in which the rats were offered water at the usual time of testing; they invariably refused it. This, plus the fact that sham intake of carbohydrates varies in expected ways with nutritional status (e.g., Mook, Wagner, \& Talley, in press), justifies our speaking of "sham feeding" rather than "sham drinking" throughout this report.

\section{Procedures}

Sham feeding. For sham-feeding experiments, the rat was attached to its tether inside the test cage. The test fluid was presented in an inverted graduated cylinder fitted with a metal drinking spout. The tip of the spout ended about $1 / 8$ in. outside the cage front. The rats were allowed to ingest offered fluid without concurrent infusion of fluid into the stomach (see below). Intake was read at 5min intervals to the nearest milliliter.

Concurrent infusion. One of the advantages of the double-fistula preparation is that it permits separation and independent variation of the oral and postingestive events that occur during a bout of feed- ing. This is done by injection of fluid into the stomach concurrent with the act of sham ingestion.

When this was done, the tether and swivel assembly were connected through flexible tubing, filled with the fluid to be infused, to a hand-held syringe. The rat was attached to its tether, and fluid was offered for sham ingestion as before.

As the rat passed fluid through the mouth and out the fistula, fluid was concurrently injected through the tubing and cannula, into the rat's stomach. Volume injected was matched to the volume lapped by continuous monitoring of cylinder and syringe calibrations.

Since the fluid tasted and the fluid injected came from different sources, their compositions could be varied independently. For example, a rat could taste a glucose solution while receiving a matched volume of nonnutritive fluid i.g.. The osmolarity of the nonnutritive fluid could be manipulated independently of that of the oral stimulus, as in the present experiments. When the injected fluid was identical to the fluid passing through the mouth, the conditions of real feeding were reinstated.

Most of the experiments reported here compared the effects of three i.g. infusates delivered concurrently with ingestion: glucose at $1 \mathrm{M}$ or $2 \mathrm{M}$, isotonic $\mathrm{NaCl}(0.15 \mathrm{M})$ as a control for nonspecific effects of infusion, and hypertonic $\mathrm{NaCl}(0.5 \mathrm{M})$, nonnutritive but osmotically active. This $\mathrm{NaCl}$ concentration was chosen because it was found earlier (Mook, 1963) to produce rapid inhibition of oral glucose intake in water-deprived rats. No attempt was made to match the osmolarities of the glucose and $\mathrm{NaCl}$ solutions delivered i.g., because the effective osmotic actions of the two solutes would be very different in any case.

\section{EXPERIMENT 1}

Experiment 1 replicated and extended the earlier demonstration of osmotic control over glucose intake (Mook, 1963).

\section{Method}

Four esophagostomized rats served as subjects. The experiment was conducted over 16 consecutive days. On each experimental day, the rats were permitted to sham feed a $2 \mathrm{M}$ glucose solution while receiving one of four i.g. conditions: no i.g. infusion (sham feeding), infusion of $2 \mathrm{M}$ glucose (real feeding), infusion of $0.15 \mathrm{M} \mathrm{NaCl}$ (approximately isotonic), and infusion of $0.5 \mathrm{M} \mathrm{NaCl}$ (hypertonic). In each case where an i.g. infusion was given, it was matched in volume and time counse with the amount ingested orally, as described above. Each condition was imposed for 4 consecutive days; order of conditions was counterbalanced. Each session lasted $40 \mathrm{~min}$.

\section{Results}

The results are shown in Figure 1. Ingestion of glucose without infusion (sham feeding) was copious, and it was only slightly depressed by i.g. infusion of isotonic saline. Real feeding, in contrast, was sharply limited. Most important, ingestion was also sharply limited when noncaloric but hypertonic fluid was infused. Intake was about as low under this condition as under the real-feeding condition.

Overall, the effect of condition was significant $[F(3,9)=$ $58.59, p<.01]$. Planned comparisons show that the isotonic $\mathrm{NaCl}$ condition did not differ significantly from sham feeding $[F(1,3)=3.97$, n.s. $]$. Real feeding was significantly depressed relative to isotonic $\mathrm{NaCl}$ infusion $[F(1,3)$ $=33.21, p<.05]$. Intake was significantly depressed when a hypertonic, relative to an isotonic, $\mathrm{NaCl}$ infusion 


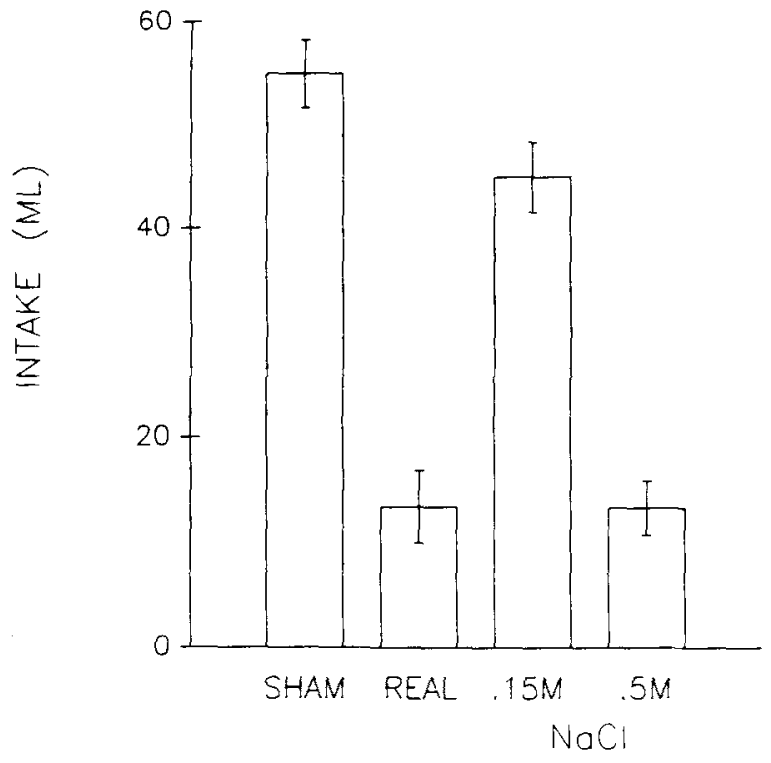

Figure 1. Oral intake of $2 \mathrm{M}$ glucose (means and standard errors) under various conditions of concurrent intragastric infusion.

was imposed $[F(1,3)=76.77, p<.01]$. This last finding shows the inhibitory effect of hypertonicity (or some correlate or consequence of this) in the absence of nutritive postingestive events.

\section{EXPERIMENT 2}

Experiment 2 was a replication and extension of Experiment 1. In Experiment 1, we observed that 2 of the 4 rats consistently fed slowly and intermittently; it was as if they were reluctant to ingest the very concentrated $2 \mathrm{M}$ glucose solution. This is not our usual finding with such rats (e.g., Mook \& Wagner, 1988), but its appearance in these 2 rats led us to repeat the experiment in the same rats with $1 \mathrm{M}$ glucose as oral stimulus, in an attempt to see more clearly the time course of discrete meals.

\section{Method}

In Experiment 2, the oral stimulus was always a 1-M glucose solution. The four i.g. conditions were as before: none (sham feeding), concurrent infusion of $1 \mathbf{M}$ glucose (real feeding), infusion of isotonic $\mathrm{NaCl}(0.15 \mathrm{M})$, or infusion of hypertonic $\mathrm{NaCl}(0.5 \mathrm{M})$. We further simplified the procedure by presenting the four i.g. conditions only twice each, in counterbalanced order, since there were no consistent effects of successive testing under constant conditions in the previous data. We also reduced the duration of the session from $\mathbf{4 0}$ to $30 \mathrm{~min}$, since an initial glucose meal is completed in well under $30 \mathrm{~min}$ in real-feeding rats.

There was one additional modification. A stomach load of hypertonic $\mathrm{NaCl}$ can stimulate water intake (e.g., McCleary, 1953), perhaps by drawing water into the gut with resulting systemic dehydration. If our effect depends on that chain of events, then inhibition of glucose intake should be accompanied or followed by behavioral signs of thirst. Therefore, after the second of the 2 days in which hypertonic $\mathrm{NaCl}$ was infused, we tested for responsiveness to water as follows: At the end of the session, a drinking cylinder containing plain water was offered and the rat was permitted to sham drink for an additional $40 \mathrm{~min}$.

\section{Results and Discussion}

The results with glucose as oral stimulus are shown in Figure 2, which presents cumulative intake curves. Sham feeding proceeded at a nearly constant rate throughout the session. When isotonic saline was infused concurrent with feeding, ingestion slowed down toward the end of the session. With infusion of hypertonic glucose or $\mathrm{NaCl}$, ingestion was limited still further. It occurred as a discrete initial meal, ending within $20 \mathrm{~min}$.

Overall, the effect of condition was significant $[F(3,9)$ $=18.97, p<.01]$. The different rates at which ingestion was inhibited by the i.g. infusions produced a significant time $\times$ condition interaction $[F(15,45)=3.53, p<.01]$.

Planned comparisons showed no significant difference in absolute intakes as between the sham and isotonic- $\mathrm{NaCl}$ conditions $[F(1,3)=4.67, \mathrm{n} . \mathrm{s}$.$] . The difference in rate$ of decline, however, did produce a significant time $\times$ condition interaction $[F(5,15)=7.13, p<.01]$. Glucose infusion (real feeding) suppressed intake relative to isotonic $\mathrm{NaCl}[F(1,3)=22.17, p<.05]$. Infusion of hypertonic $\mathrm{NaCl}$ again produced greater suppression than did the isotonic infusion $[F(1,3)=68.72, p<.01]$.

The data support and extend the major finding of Experiment 1: A hypertonic i.g. infusion, even if nonnutritive, rapidly inhibits ingestion of glucose. Here, we see its effect on a single initial meal, taken at the outset of the session. It brought the meal to an end about as rapidly as i.g. glucose itself did.

This effect was unaccompanied by behavioral signs of thirst, as shown by the test for responsiveness to water after the second of the hypertonic- $\mathrm{NaCl}$ sessions. When water was made available, all rats sampled it and took brief sham draughts. They quickly abandoned the cylinder,

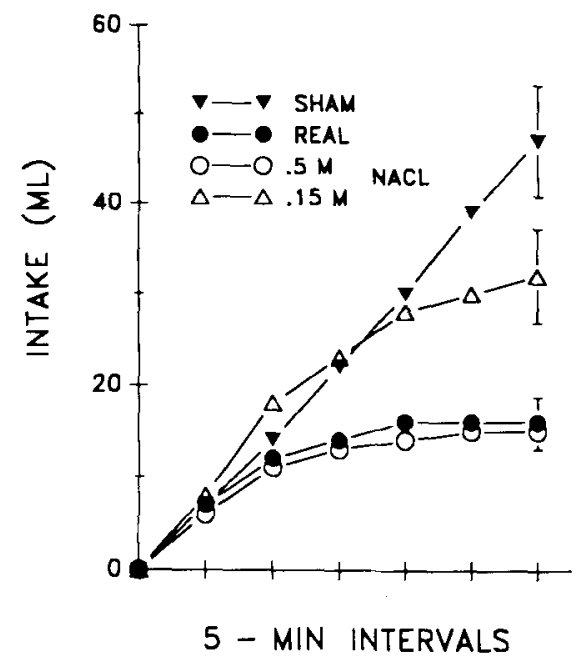

Figure 2. Cumulative oral intake of $1 \mathrm{M}$ glucose (means and standard errors) under various conditions of concurrent intragastric infusion. 
however, after sham drinking a mean of $2.25 \mathrm{ml}$ (range 1-3 ml). This was so even though no water was delivered into the body with the drinking. In this case, it is true that taste-contrast effects might have worked against responsiveness to water, because the water test followed a period of access to glucose. The fact remains that there was no sign of the vigorous and persistent sham drinking expressed by water-deprived rats when water is offered (e.g., Mook \& Wagner, 1988).

\section{EXPERIMENT 3}

In Experiments 1 and 2, we held the oral stimulus constant while varying the postingestive condition. In Experiment 3, we varied the intensity of the oral stimulus while holding postingestive events constant. We compared two such sets of postingestive conditions: hypertonic glucose and hypertonic but nonnutritive $\mathrm{NaCl}$.

\section{Method}

Using the same 4 animals that were used in Experiments 1 and 2, this experiment was conducted over two 4-day periods. Within each period, the oral stimulus was $2,1,0.5$, and $0.25 \mathrm{M}$ glucose, presented once each in descending order. Concurrent i.g. feeding was held constant at $1 \mathrm{M}$ glucose for one 4-day period, and $0.5 \mathrm{M} \mathrm{NaCl}$ for the other, in counterbalanced order.

\section{Results and Discussion}

The results are shown in Figure 3. With both postingestive conditions, intake increased with oral glucose concentration, just as sham feeding does (Mook \& Wagner, 1988). The effect of concentration was significant $[F(3,9)$ $=15.11, p<.01]$. The two conditions did not differ significantly, and there was no interaction (both $F$ s $<1$ ). In all conditions, the intake values reflected the termination of the initial meal; once initial ingestion had ceased, further feeding was minimal, if it occurred at all.

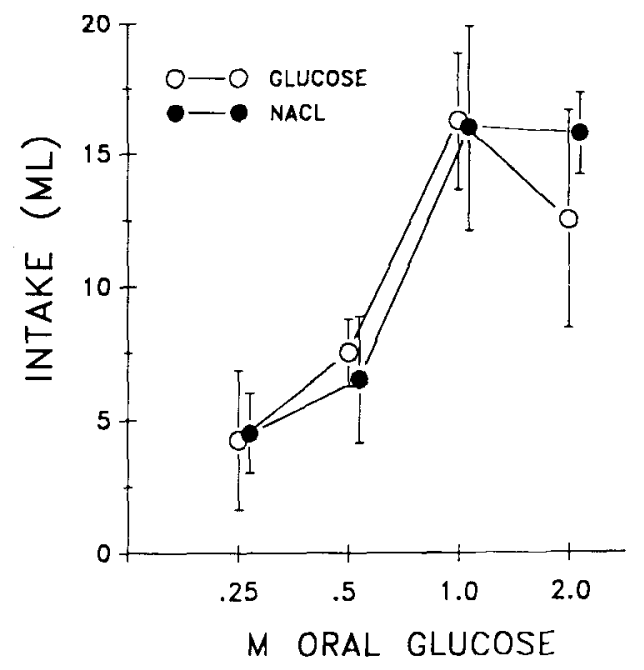

Figure 3. Oral intake of glucose (means and standard errors) as a function of concentration, with matched infusions of $1 \mathrm{M}$ glucose or $0.5 \mathrm{M} \mathrm{NaCl}$.
It is worth noting that intake at all concentrations was much lower than the values seen in sham-feeding rats comparably deprived (Mook \& Wagner, 1988). We did not include a sham condition in Experiment 3, because our interest was in the slope, not the height, of the intakeconcentration function (see below); however, comparison of these data with others shows clearly that the control was postingestive.

These data suggest two conclusions: (1) the approximate equivalence of glucose and hypertonic $\mathrm{NaCl}$, as postingestive stimuli, extends across a range of intensities of the oral stimulus, and (2) decreasing that intensity leads to earlier termination of the ingestive bout under both i.g. conditions.

These data are different from earlier findings with a similar method (Mook, 1963). In the earlier experiment, i.g. infusion of hypertonic $\mathrm{NaCl}$ greatly augmented intake when a dilute glucose solution, or water, was presented to the mouth. The result was that intake became a decreasing, rather than increasing, function of oral glucose concentration. Nothing of the sort happened in the present experiment. With hypertonic i.g. infusions, the size of the ingestion bout increased with oral glucose concentration, just as it does in the sham-feeding case (Mook \& Wagner, 1988).

Those earlier rats were water deprived, however, and their intake of water, as well as of sweet solutions, was substantial even without the hypertonic i.g. load. For the earlier findings, it was suggested that hypertonic infusions started a positive-feedback cycle: they aggravated the rats' dehydration, causing further drinking of dilute solutions (or water), resulting in more infusion and still further dehydration. That would imply that the present rats, which were not dehydrated at the outset, simply did not ingest enough of the dilute fluids to set the positive-feedback loop in motion. Therefore, the present pattern is a further indication that the hypertonic i.g. loads suppress glucose sham feeding before they evoke thirst.

\section{EXPERIMENT 4}

Experiment 4 was a control experiment, to test the possibility that the sharply limited intakes we observed with hypertonic $\mathrm{NaCl}$ infusion resulted from behavioral incompetence. We have observed no signs of distress or debility in these experiments, but a direct demonstration is obviously desirable.

Rats that have ingested glucose to satiety, and will take no more of it if access is extended, are nonetheless willing to ingest a milk-based liquid diet with avidity (see Mook, 1988). The same is true, we now show, of rats in which the initial satiety is produced by a nonnutritive $\mathrm{NaCl}$ load. Therefore, the initial satiety is not a matter of inability to ingest.

\section{Method}

Again using the same 4 animals, the experiment was conducted on 2 successive days. On both, for the first $30 \mathrm{~min}$ of the session, the rat was offered $1 \mathrm{M}$ glucose to ingest by mouth, receiving 
matched infusions of $0.5 \mathrm{M} \mathrm{NaCl}$ i.g. Then, for a second 30-min period, the rat was offered either continued access to $1 \mathrm{M}$ glucose (with removal and replacement of the drinking cylinder) or the milkbased liquid diet that was their maintenance food, diluted by half with water. Ingestion was sham in both cases. The two conditions were imposed in counterbalanced order.

\section{Results and Discussion}

In the first $30 \mathrm{~min}$, an average of $11.5 \mathrm{ml}$ was ingested, a value comparable to the equivalent data point in Experiment 3. Over the second 30 -min period, no rat took a measurable amount of glucose, though all sampled it before rejecting it. All rats accepted the milk, however, sham eating an average of $15.75 \mathrm{ml}$ (range 5-39 ml). Clearly, the rapid termination of the glucose meal, when $\mathrm{NaCl}$ was infused, did not reflect inability to ingest.

It is of some interest that the rats accepted milk after expressing satiety for glucose. We have seen a similar phenomenon in real-feeding rats (Mook, Brane, GonderFrederick, \& Whitt, 1986). There are several factors that might have produced it in this case. First, the greater palatability of the milk may have sufficed to maintain ingestion for a while. Second, the change in commodity per se might have been important, reflecting a "sensory-specific satiety." Third, the postingestive effects of hypertonic $\mathrm{NaCl}$ may be selective, inhibiting intake of some foods but not of others; such postingestive specificity has been demonstrated directly, but with other commodities (Mook, Dreifuss, \& Keats, 1986). The latter possibility is addressed in Experiment 5.

\section{EXPERDMENT 5}

The rats' ready acceptance of the milk diet, after the $\mathrm{NaCl}$ load, led us to wonder whether ingestion of this complex diet would also be subject to the nonnutritive inhibitory factor implicated by the previous experiments. We therefore extended the investigation to that diet as oral stimulus. Does responsiveness to milk escape the inhibitory effects of hypertonicity? It does not.

\section{Method}

Three rats were used. Two of them had served in the previous series of experiments; the third had not.

The procedure was a simple modification of Experiment 2 . The liquid diet by which such rats are maintained, diluted by half with water, was offered for ingestion for a 40-min period. The four i.g. infusion conditions were as follows: none (sham feeding), isotonic $\mathrm{NaCl}(0.15 \mathrm{M}), 1 \mathrm{M}$ glucose, and hypertonic $\mathrm{NaCl}(0.5 \mathrm{M})$. As before, when infusions were given, their volumes were continuously matched with those sham ingested. The conditions were imposed twice each in counterbalanced order.

\section{Results and Discussion}

Results for individual animals, averaged across the two sessions with each condition, are shown in Figure 4. In every rat, the pattern is the same. Sham feeding is reduced by isotonic- $\mathrm{NaCl}$ infusions, and it is reduced further by the other two postingestive conditions: glucose and hypertonic $\mathrm{NaCl}$. Differences between the latter two conditions are relatively small and inconsistent as to direction.

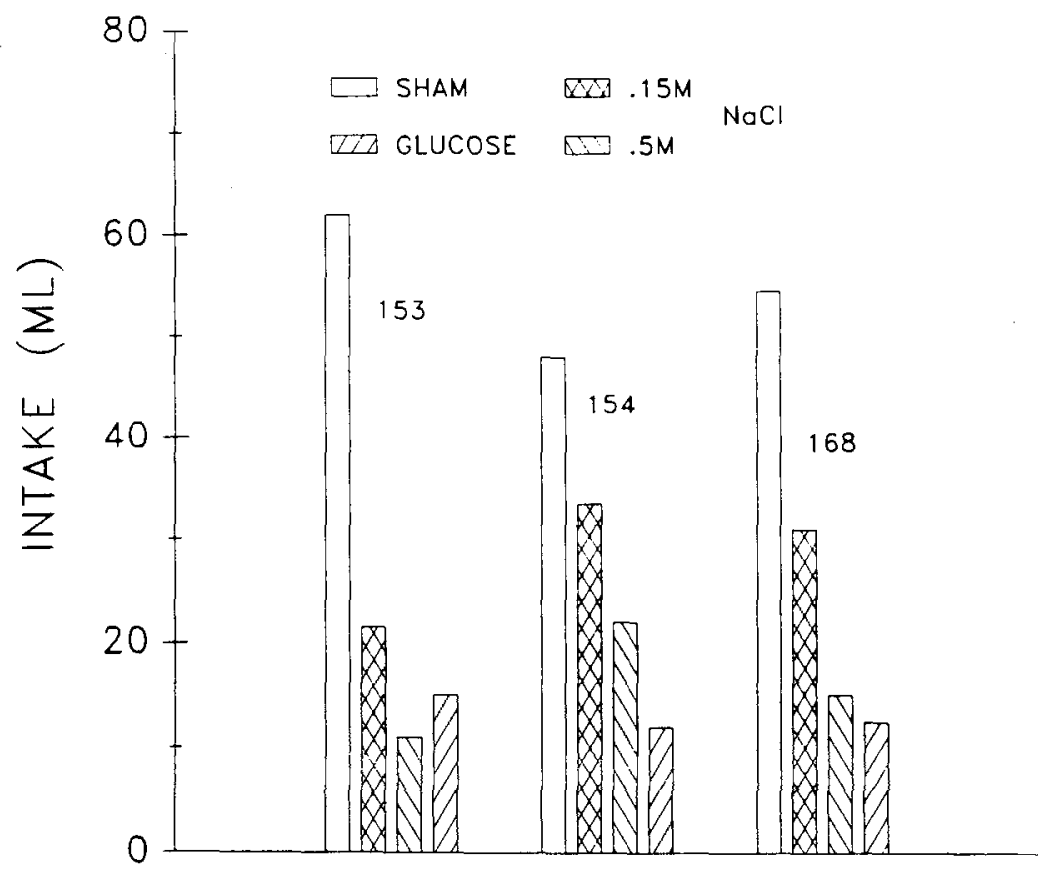

Figure 4. Oral intake of liquid diet under various conditions of concurrent intragastric infusion. Numbers designate individual rats. 
So consistent are the data that, even with this very small sample, the important differences are statistically reliable. Planned comparisons show the following: Intake with isotonic- $\mathrm{NaCl}$ infusion is less than sham intake $[t(2)=$ $3.43, p<.05$ ], demonstrating nonspecific postingestive control. Intake is lower with glucose infusion than with isotonic $\mathrm{NaCl}[t(2)=7.48, p<.01]$. Intake is lower with hypertonic $\mathrm{NaCl}$ than with isotonic $[t(2)=3.38, p<$ $.05]$, demonstrating the effect of hypertonicity or its correlate. (All ps are one-tailed.)

\section{GENERAL DISCUSSION}

These data confirm and extend our earlier findings with this procedure (Mook, 1963) and the still earlier findings of McCleary (1953). First, hypertonic stomach loads, even if nonnutritive, can rapidly suppress the ingestion of glucose solutions. Indeed, in these experiments as well as in our earlier ones, we find that glucose ingestion is terminated as rapidly by the postingestive effects of hypertonic $\mathrm{NaCl}$ as by those of glucose itself. Second, the suppressant effect of a hypertonic stomach load is also expressed when a complex liquid diet, rather than a glucose solution, is presented to the mouth.

The data also show that the osmotic inhibition can be expressed even when responsiveness to water is neither present at the outset nor induced by the hypertonic infusate. It is separable, in other words, from induction of thirst.

That hypertonicity of the infusate can suppress sham feeding does not, of course, imply that it is the only postingestive influence that does so. In particular, we make no claim that hypertonic glucose solutions lead to rapid inhibition because they are hypertonic (cf. Jacobs, 1964). We do know that infusions of material that is nutritive, but not hypertonic, can also suppress sweet-solution intake (e.g., Campbell \& Davis, 1974). It is most likely, therefore, that either chemospecific or osmotic events can act to suppress further glucose feeding; either mechanism is sufficient, and neither is necessary.

We do not yet know just where or how this effect of hypertonicity is exerted. It might be mediated by osmoreceptors in the periphery or even in the brain; thus, intake of solid food can be suppressed by intraperitoneal injections of hypertonic $\mathrm{NaCl}$, bypassing the GI tract (e.g., Oatley \& Toates, 1973). Or it might not depend directly on osmoreception at all; for example, it could reflect gastric distension produced by influx of fluid into the gut (Davis, Collins, \& Levine, 1975). Sham-feeding experiments in which concurrent infusions bypass the gut, as well as the mouth, can begin to dissociate these possibilities.

\section{REFERENCES}

CAmpbell, C. S., \& DAVIS, J. D. (1974). Licking rate in rats reduced by intraduodenal and intraportal glucose infusion. Physiology \& Behavior, 12, 357-365.

Davis, J. D., Coluins, B. J., \& Levine, M. W. (1975). Peripheral control of drinking: Gastrointestinal filling as a negative feedback signal, a theoretical and experimental analysis. Joumal of Comparative \& Physiological Psychology, 89, 985-1002.

DAvis, J. D., \& SMTTH, G. P. (1990). Leaming to sham feed: Behavioral adjustments to loss of physiological postingestive stimuli. American Journal of Physiology, 259, R1228-R1235.

JACOBS, H. L. (1964). Evaluation of the osmotic effects of glucose loads in food satiation. Joumal of Comparative \& Physiological Psychology, 57, 309-310.

MCCleary, R. A. (1953). Taste and postingestion factors in specifichunger behavior. Joumal of Comparative \& Physiological Psychol$o g y, 46,411-421$.

Mook, D. G. (1963). Oral and postingestional determinants of the intake of various solutions in rats with esophageal fistulas. Joumal of Comparative \& Physiological Psychology, 56, 645-659.

Mook, D. G. (1988). On the organization of satiety. Appetize, 11, 27-39.

Mook, D. G., Brune, J. A., Gonder-Frederick, L., \& Witr, J. A. (1986). Satieties and cross-satieties for three diets in the rat. Physiology \& Behavior, 36, 887-895.

Mook, D. G., Dreiruss, S., \& Keats, P. H. (1986). Satiety for glucose solution in rat: The specificity is postingestive. Physiology \& Behavior, 36, 897-901.

MoOK, D. G., WAGNER, S. (1987). Preparation and maintenance of rats with esophagostomy and gastric cainnula. Physiology \& Behavior, 39, 417-420.

Mook, D. G., WAGNER, S. (1988). Glucose sham-drinking in rat: Some effects of hydration. Appetite, 10, 71-87.

MooK, D. G., Wagner, S., Hartune, D. F. (1991). All-or-none suppression of glucose sham feeding by an intragastric mixed meal in rats. Behavioral Neuroscience, 105, 712-720.

Mook, D. G., WAGNer, S., TALLEY, C. L. (in press). Effect of imposed body-weight variation on glucose sham feeding in rat. Appetite.

OAtLEY, K., * TOATES, F. M. (1973). Osmotic inhibition of eating as a subtractive process. Joumal of Comparative \& Physiological Psychology, 82, 263-277.

WeIngarten, H. P., Watson, S. D. (1982). Sham-feeding as a procedure for assessing the influence of diet palatability on food intake. Physiology \& Behavior, 28, 401-407.

(Manuscript received May 22, 1991; revision accepted for publication October 8, 1991.) 